\title{
Comparison of AC-Superconducting Multi-Phase Symmetric-Winding Topologies for Wind Power Generators with Passive PM Rotors
}

\author{
Dany Tomé, Graduate Student Member, IEEE, Robert Nilssen, and Jonas Kristiansen Nøland, Member, IEEE
}

\begin{abstract}
In this paper, an AC superconducting multi-phase symmetric-winding machine is designed for a wind power generator to improve its performance and reduce losses, where four handpicked topological designs were explored and compared. In particular, it is found that using high-phase order of unique phasors further improves the performance. The iron losses are reduced, and the rippling behaviour is reduced due to the smoother airgap magnetic flux density. Furthermore, a higher LCM is achieved due to a better slot-pole combination for fractional slot concentrated windings without having space subharmonics. Nonetheless, it is shown that creating a smooth air gap magnetic flux density does not improve the AC hysteretic superconducting losses; thus, further analysis with another approach must be done. Moreover, it is found that the Meisner effect is present in the machine and is inversely proportional to the AC hysteretic superconducting losses. Finally, it shows that a 13-phase AC-superconducting machine can achieve a theoretical limit approaching $101.7017 \mathrm{Nm} / \mathrm{kg}$ for the torqueto-weight (TTW) ratio, outperforming classic winding layouts.
\end{abstract}

Index Terms-Superconducting coils, AC losses, Multiphase symmetric windings, Iron losses, Fractional Slot Concentrated Windings, Harmonics.

\section{INTRODUCTION}

$\mathbf{N}$ Owadays, the electric sector is changing rapidly towards a more sustainable energy supply. In particular, the growth of offshore wind power generation has been driven towards bigger wind turbines. Thus, the challenge to create more compact and lightweight structures and machines have become a necessity for the industry.

One of the technologies that have been investigated to create compact generators in recent years is electrical machines (EMs) made with superconductors. Recently three projects have been developed to prove the feasibility of DC-based superconducting machines (SCMs), i.e., a superconducting field winding to enhance the magnetic loading of the machine. Those are INNWIND [1], Suprapower [2], and EcoSwing [3]. The latter has been successfully proved with a technology readiness level (TRL) equal to 7 , achieving an airgap shear stress that doubles compared to a permanent magnet generator (PMG) and a weight reduction up to $24 \%$. In addition, there has been documentation on the reliability and robustness of the generator design [1]-[7].

D. Tomé is a Master's student of the European Wind Energy Master (EWEM) at TU Delft and NTNU

J. Nøland and R. Nilssen are professors from NTNU

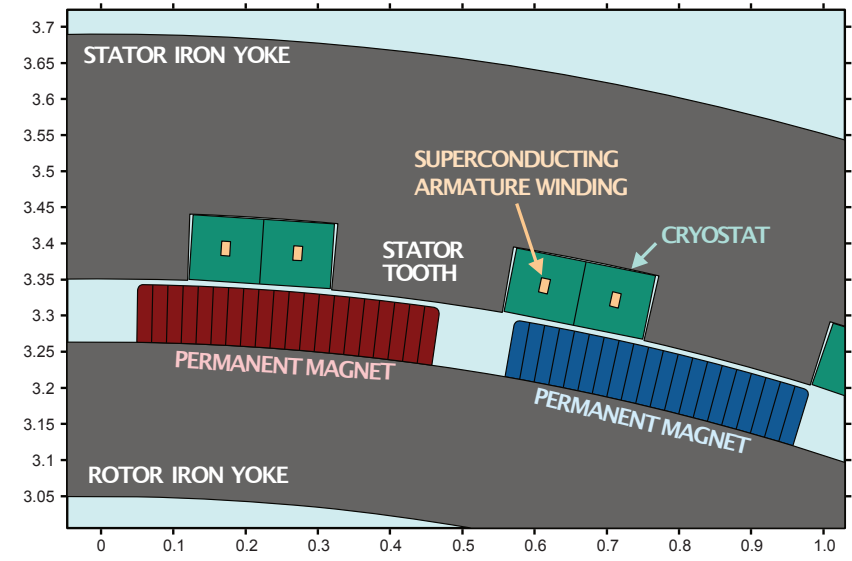

Fig. 1. Illustration of wind generator's machine geometry considered in the paper with slots designed according to cryostat requirements.

Further development of fully superconducting solutions has been achieved for low-speed machines, in which the low electrical frequency cause the $\mathrm{AC}$ losses to decrease. Moreover, it is reported that one strategy to minimize total AC loss is by increasing airgap flux density as a result of reducing the armature current needs, which also gives a safety margin to avoid quenching [8]. However, fully superconducting generators require a rotating cryostat which makes them more difficult to manufacture.

PM superconducting wind power generators do not have moving cryostat. However, the main issue is the demagnetization of the PMs, which is strogly related to the interaction with the stator slot design. It is influences by the PM dimensions and the current applied to the superconducting (SC) coils, which is the source of the magnetomotive force (MMF) for demagnetization. In order to avoid the demagnetization of the PMs, the MMF produced by the SC coil is restricted. In particular, the airgap flux density is tried to be ket at least $B_{\delta} \geq 0.25 T$ [9]. Also, it has been proved that an iron-cored, both stator and rotor, has better output torque capability and higher efficiency, compared to an iron-cored rotor air-cored stator [9]. Moreover, slotted machines give better support to the coils, higher main flux and save SC material. Fig. 1 depicts an example topology, which will be further explored herein.

Another remarkable technology to improve the performance and compactness is multiphase electrical machines (MEMs), which have been slightly assessed in prior studies. Nonetheless, the major research focus has been on asymmetric wind- 
ings, which have multiple sets of m-phase windings, letting aside the symmetric windings of high-phase order. The main difference in having symmetric windings is that they are electromagnetically coupled with all the phases. In contrast, multiple asymmetrical sets of windings are magnetically coupled and electrically isolated in [10]. Furthermore, related to power electronics, symmetric multiphase windings required control of only one electrical system, while asymmetric ones must control multiple electrical systems.

A higher number of phases can produce a more sinusoidal magnetic field than a machine with fewer phases, even if it has a similar number of slots. Also, its harmonics that contribute to useful "saturation harmonics". Extra torque contributions are obtained because the air gap's flux distribution is flattened, avoiding the iron saturation and achieving a wider operational range. In summary, a MEM improves torque density, decreases cogging torque, reduces ripples, reduces rotor losses, and is more fault-tolerant [11]-[14].

This paper performs an investigation into ACsuperconducting Multi-Phase Symmetric-Winding Topologies for wind power generators with passive PM rotors to achieve compactness and feasibility. The usage of PM machines contributes to two utmost questions. 1) The performance of multiphase superconducting PM machines; and 2) The effects of smoother magnetic fluxes into the AC armature superconducting coils. The in-depth study is provided in the finite element analysis (FEA) environment.

The present paper is divided into the following five sections. Section II discusses the multiphase winding layouts and the design theory of high-phase order symmetric windings. Moreover, four windings layouts are taken as case designs and compared to assess the multiphase windings. In Section III, the SCMs, their theory, and the formulation behind their superconductivity behaviour are addressed. Finally, Section IV presents the main analysis and results before the paper is concluded in Section V.

\section{Multiphase Winding LAYOUTS}

A double-layer fractional-slot concentrated-winding (DLFSCW) was conveniently selected to compare the various multiphase topologies easily. In comparison, an integer slot winding layout requires different arrangements of poles. The larger the number of phases, the smaller the number of poles, which means lower electrical frequencies and more superconductive material. It is also worth mentioning that a stator with many slots is not possible because of the bending constraints of the superconducting armature coils, which makes a case for the chosen DL-FSCW. For the case of winding layout design of $\mathrm{m}$-phase fractional slot windings, it is useful to comply with specific conditions. First, $\mathrm{q}$ has to be reduced so that the numerator and the denominator are the smallest possible integers as follows,

$$
q_{s}=\frac{Q_{s}}{p m}=\frac{z}{b}
$$

where $Q_{s}$ is the total number of slots, $p$ is the number of poles, $m$ is the number of phases, and $q_{s}$ is the number of slots per pole and phase.

\section{A. Conditions of Symmetry}

To comply with symmetrical winding for the DL-FSCW, the three following conditions must be fulfilled.

1) First condition of symmetry: For double-layer windings, the first condition of symmetry requires that in the equation

$$
\frac{Q_{s}}{m}=p q_{s}=p \frac{z}{b}, \quad \frac{p}{b} \in \mathbb{N}
$$

2) Second condition of symmetry: This condition is related to the divider $t$ of $Q_{s}$ and $p$. Which, in the end, can be written simply in the form: $b$ and $m$ cannot have a common divider.

$$
\frac{b}{m} \notin \mathbb{N}
$$

3) Third condition of symmetry: For a 24-phase winding, with $Q_{s}=48$ and $p=40, q_{s}=1 / 20$ is obtained, complying with the first and second symmetry condition. However, it does not generate 24 symmetric phases. Thus, the third condition for symmetry is proposed as follows:

$$
\frac{Q_{s}^{\prime}}{m} \in \mathbb{N}
$$

Which states that to achieve a multiphase winding, the slots per phase in a base winding shall be an integer number. The number of slots of a base winding is calculated as follows:

$$
Q_{s}^{\prime}=\frac{Q_{s}}{t}=\frac{Q_{s}}{G C D\left(Q_{s}, p / 2\right)}
$$

For instance, if a 9-phase machine wants to be constructed with a $Q_{s}=48$ and $p=40$, it is impossible because the number of slots per phase is fractional. Thus, a stator in which $Q_{s}$ is not multiple of m cannot be constructed. Hence, a slotpole combination of $Q_{s}=45$ and $p=40$ will have 1 slot per phase, which gives a well designed multiphase machine.

\section{B. Multiphase Winding Design}

The reference machine is taken from Dong Liu et al [15], [16]. Which is a 48 slots and 40 poles. With this the base winding are calculated, and the winding layouts are designed as follows.

1) 12-phase winding layout: A 12-phase winding layout is selected because it is the highest possible number of phases with the same geometry as a 3-phase winding layout. Both winding layouts are shown in figure 2. Thus, the comparison between them is more straightforward, meaning that the only difference between the two geometries is how the coils are connected. Further, it is essential to notice that the configuration layout has 12 coils as a symmetric winding design. However, there are only six unique phasors, resulting in a dual-six-phase machine.

2) 24-phase winding layout: A 24-phase winding is designed to endorse the finding of the 12-phase machine because it doubles the number of phases. Thus, in principle, the performance enhancement is superior. Moreover, the 24-phase symmetric winding layout has twelve unique phasors, resulting in a dual-twelve-phase machine. 

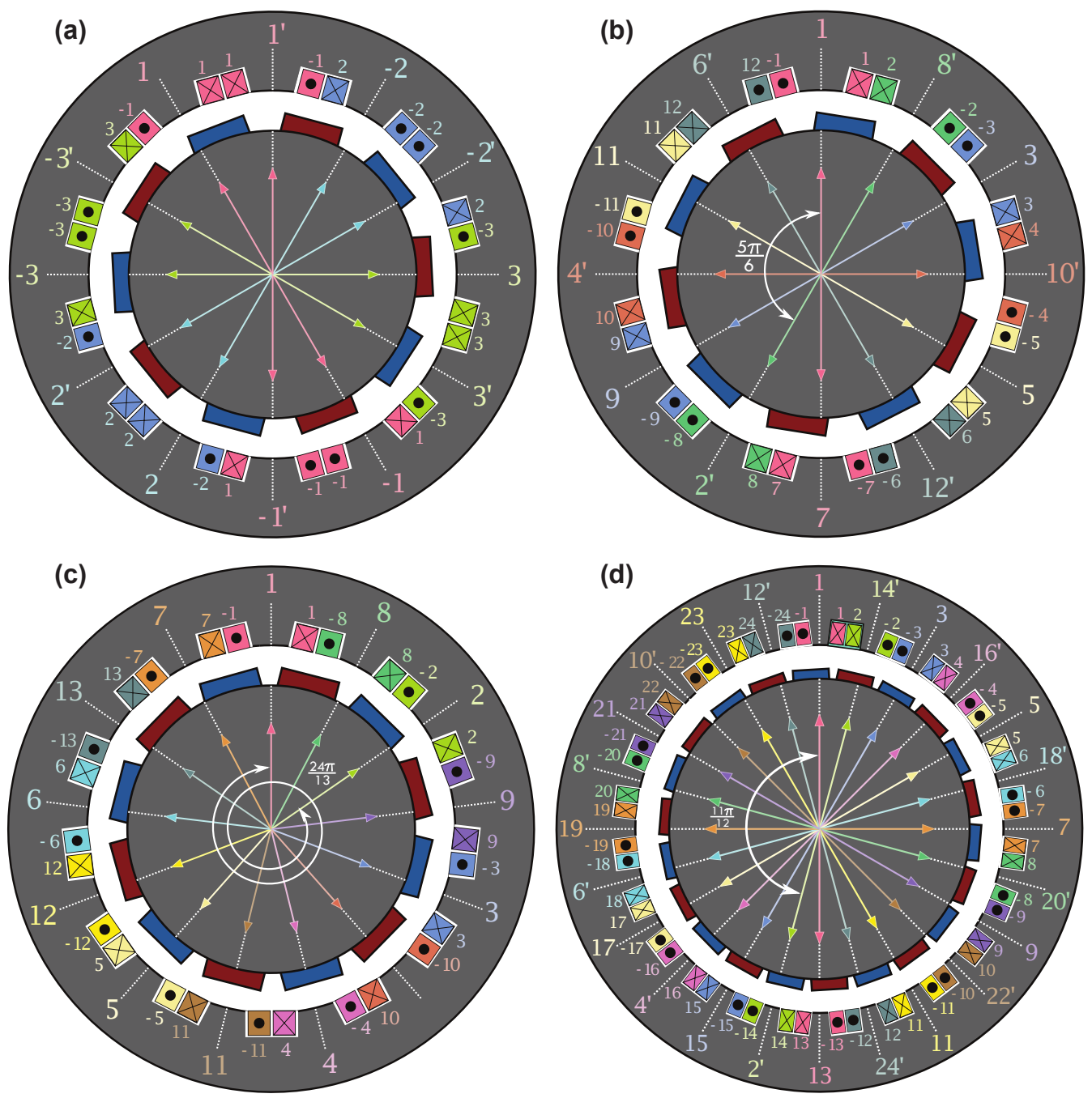

Fig. 2. Base winding topologies of different multiphase configurations. (a) 3-phase. (b) 12-phase (dual 6-phase). (c) 13-phase. (d) 24-phase (dual 12-phase).

3) 13-phase winding layout: Furthermore, a 13-phase winding layout shows that having a high order of unique phasors (odd phase number) is the most intelligent way to design a symmetric multiphase winding. Because the 24phase machine only has 12 unique phasors. Hence, a 13phase machine with 13 unique phasors enhances further the machine's performance.

\section{SUPERCONDUCTING COIL}

A superconductor's main characteristic properties are its high conductivity and the expelling of the magnetic field fluxes from the core material. These originate a zero DC resistance under specific conditions of 1) the temperature, 2) the critical current, 3) the magnetic field inside the material, and 4) its pressure. The latter property is particularly essential for room temperature superconductivity [17], while the others are important for low and high-temperature superconductivity $(4-77 K)$.

The first three parameters presented in Table I must be within the critical range to avoid quenching of the superconductivity. This depends on the superconducting material characteristics and the fabrication process. For use in EMs, the superconducting $\mathrm{AC}$ losses have to be reduced to obtain a good performance of the generator or motor. In particular, $M_{g} B_{2}$ is a good candidate due to low AC losses, and low price [18]. However, this wire is produced with a cylindrical shape, which means that the magnetic field fluxes are isotropic around the whole material, yet this is true for one wire. For EM applications, the coils are constructed with several wires in which the penetration of magnetic field fluxes depends on the arrangements of the wire in the coil. Thus, the losses will depend on these topological arrangements. For model simplicity and computability purposes, a high-temperature rectangular bulk superconductor wire is considered herein.

A typical superconductor wire is constructed with 4 layers arranged according to the geometry to improve stability, strength, and insulation, as shown in Fig. 3. Having these layers, 4 types of losses taking place in the wire, e.g., 1) eddy current losses due to conducting layers; 2) coupling losses along with the metal layer between superconducting material filaments; 3) ferromagnetic losses that are the hysteresis losses of the metal itself; 4) superconducting hysteresis losses due to varying fields. For the present paper, only the latter is considered. 
TABLE I

Model PARAMETERS FOR EQS. (6)-(8) REPRESENTING THE SUPERCONDUCTING WIRE

\begin{tabular}{lll}
\hline \hline Symbol & Quantity & Value \\
\hline$\sigma_{c}$ & critical conductivity & $3.2444 \times 10^{12} \mathrm{~S} / \mathrm{m}$ \\
$E_{c}$ & critical electric field & $1 \times 10^{-4} \mathrm{~V} / \mathrm{m}$ \\
$J_{c}$ & critical engineering current density $^{1}$ & $324.44 \mathrm{~A} / \mathrm{mm}^{2}$ \\
$n$ & exponent factor $^{1}$ & 25 \\
\hline \hline
\end{tabular}

${ }^{1}$ The exponent factor is handpicked to be in between $M g B_{2}$ and REBCO typical values [19], [20].

The E-J power-law is used to formulate the superconductor's conductivity to properly model its interaction with the magnetic vector potential formulation in the COMSOL finite element analysis (FEA) environment (rotating magnetic machinery module). Moreover, in order to account for the nonbounder origin [21], the following consideration is made.

$$
\begin{gathered}
J_{c}=\sigma_{c} E_{c} \\
|\mathbf{E}|=E_{c}\left(\frac{|\mathbf{J}|}{J_{c}}\right)^{n} \\
\sigma(|\mathbf{E}|)=\sigma_{c}\left|\frac{|\mathbf{E}|-E_{c}}{E_{c}}\right|^{1 / n-1}
\end{gathered}
$$

The parameters used in eqs. (6)-(8) are given in Table I. For the case of the AC losses $\left(P_{A C}\right)$, the superconductor material is assumed to be the entire geometry of the coil. The local current density variable $\mathbf{J}$ is computed as the engineering current density to account for the percentage of superconducting material in the whole wire. Thus, the losses are determined only by hysteresis behaviour by the following expression

$$
P_{A C}=\frac{1}{T} \int_{t_{0}}^{t_{0}+T}\left[\iint_{S} \mathbf{J} \cdot \mathbf{E} d S\right] d t,
$$

where the integration is taken over the conductor's crosssectional area. In order to account for the transient phenomena due to the bounded origin condition, the $t_{0}$ for the integration of eq. (9) is postponed to the steady-state condition is reached. An existing superconductor model from [22]-[24] is used as a reference geometry for this paper. The width and height are increased to be more manageable and achieve a higher critical current as shown in Fig. 3. The coil is modeled as a bulk superconductive surface with an engineering current density $(\mathbf{J})$. The coil's geometry with its 15 turns $\left(n_{\text {coil }}\right)$ is depicted in Fig. 3, where 4 parallel wires are incorporated in the total area of one turn to handle the rated current. With this new geometry, the following obtained values are given in Table II. All the machine's configurations are designed and simulated with 15 turns per coil and $4500 \mathrm{~A}$ as nominal current. The armature's coils are modelled radially aligned for easier construction of the superconductor's racetrack.

\section{Topological Performance Analysis}

The topologies are simulated with the specifications shown in Tables III, IV and V, with a machine geometry already depicted in Fig. 1 above. For a surface-mounted PM machine, the torque is as follows.
TABLE II

Key Geometrical Quantities and EleCtrical Characteristics OF THE SUPERCONDUCTING WIRE

\begin{tabular}{lll}
\hline \hline Symbol & Quantity & Value \\
\hline$h_{s c}$ & height of turn & $20.0 \mathrm{~mm}$ \\
$w_{s c}$ & width of turn & $0.8 \mathrm{~mm}$ \\
$A_{s c}$ & cross-sectional area of turn & $16.0 \mathrm{~mm}^{2}$ \\
$w_{c o i l}$ & coil width & $12.0 \mathrm{~mm}$ \\
$I_{s}$ & strand critical current & $162.2 \mathrm{~A}$ \\
$c_{s}$ & no. of parallel strands & 8 \\
$I_{c}$ & wire critical current & $1297.7 \mathrm{~A}$ \\
$I_{w}$ & wire current & $1125.0 \mathrm{~A}$ \\
$i_{w}$ & normalized transport current $\left(I_{w} / I_{c}\right)$ & 0.867 \\
$c_{w}$ & no. of parallel wires ${ }^{1}$ & 4 \\
\hline \hline
\end{tabular}

${ }^{1}$ The number of parallel wires required to avoid superconducting quenching.

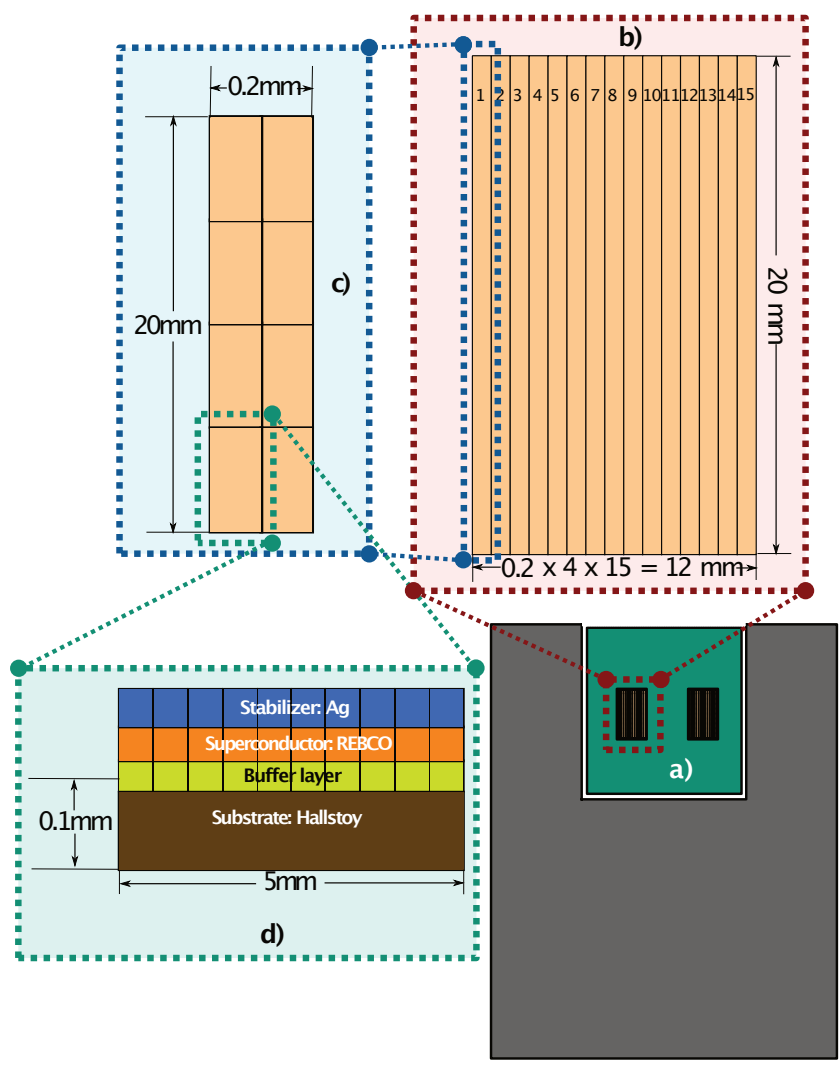

Fig. 3. a) SC coils tangentially arranged inside machine's slots, b) SC coil with its 15 turns, modelled as a bulk superconductive surface $\left(I_{r}=4500 \mathrm{~A}\right)$, c) A resized SC wire that represent a quarter of one turn $\left(I_{c}=1297.7 A\right)$, and d) SC real strand with its 4 layers for stability, strength and insulation $\left(I_{s}=162.2 A\right)$.

$$
\begin{gathered}
T=\frac{m}{4} \cdot p \cdot \Psi_{m} \cdot i_{q} \\
P=\frac{2}{p} \cdot \omega \cdot T
\end{gathered}
$$

Here, $\Psi_{m}$ is the flux linkage of the magnet in the d-axis direction and $i_{q}$ is the current magnitude aligned in the q-axis. A maximum torque per ampere approach is targeted by aligning the current with the back-EMF voltage (i.e., q-current). This optimal angle is tracked to provide the basis for performing the dq0-transformation in the COMSOL Multiphysics numerical 
TABLE III

RATED SPECIFICATION OF THE HANDPICKED WIND POWER GENERATOR

\begin{tabular}{lll}
\hline \hline Symbol & Description & Value \\
\hline$P$ & electrical power $^{1}$ & $15.00 \mathrm{MW}$ \\
$U$ & terminal voltage (rms) & $3300 / \sqrt{3} \mathrm{~V}$ \\
$I$ & phase current (rms) & $4500 / \sqrt{2} \mathrm{~A}$ \\
$S$ & apparent power & $18.19 \mathrm{MVA}$ \\
$\cos (\varphi)$ & power factor & 0.825 \\
$n$ & mechanical speed $^{2}$ & $72.2 \mathrm{r} / \mathrm{min}$ \\
$T$ & mechanical torque & $18.95 \mathrm{MNm}$ \\
\hline \hline${ }^{1}$ A $15 \mathrm{MW}$ machine is chosen because it is the \\
biggest wind turbine reference model by the In- \\
ternational Energy Agency (IEA) [25]. \\
${ }^{2}$ The mechanical speed is obtain from the reference \\
model.
\end{tabular}

TABLE IV

DESIGN SPECIFICATIONS OF THE HANDPICKED WIND POWER GENERATOR

\begin{tabular}{lll}
\hline \hline Symbol & Description & Value \\
\hline$D_{\delta}$ & air gap bore diameter & $6693.8 \mathrm{~mm}$ \\
$l_{a}$ & machine's active length & $1.5061 \mathrm{~m}$ \\
$B_{r}$ & remanent magnet flux density & $1.47 \mathrm{~T}$ \\
$l_{m}$ & magnet's height & $80 \mathrm{~mm}$ \\
$\alpha_{m}$ & magnet's coverage ratio & 0.8 \\
$N_{\text {coil }}$ & number of turns per coil ${ }^{1}$ & 15 \\
$w_{\text {cryo }}$ & Cryostat's width & $100 \mathrm{~mm}$ \\
$h_{\text {cryo }}$ & Cryostat's height & $92 \mathrm{~mm}$ \\
\hline \hline
\end{tabular}

${ }^{1}$ The number of turns is obtained using the design equations. [26]

TABLE V

INVESTIGATED WINDING DESIGNS FOR THE WIND POWER GENERATOR

\begin{tabular}{llllll}
\hline \hline Symbol & Description & \#3ph & \#12ph & \#13ph & \#24ph \\
\hline$m$ & no. of phases & 3 & 12 & 13 & 24 \\
$p$ & no. of poles & 40 & 40 & 48 & 44 \\
$Q_{s}$ & no. of slots & 48 & 48 & 52 & 48 \\
$q_{s}$ & slots per pole \& phase & $2 / 5$ & $1 / 10$ & $1 / 12$ & $1 / 22$ \\
$N_{p h}$ & no. of turns per phase & 240 & 60 & 60 & 30 \\
$k_{w d g}$ & Winding factor & 0.9330 & 0.9659 & 0.9927 & 0.9914 \\
$L C M$ & $L C M\left(Q_{s}, p\right)^{1}$ & 240 & 240 & 624 & 528 \\
\hline \hline
\end{tabular}

${ }^{1}$ The least common multiple between the number of slots and poles gives the cogging torque's empirical "goodness" value. The higher, the better. [27]

environment. Using the dq-transformed voltages, the power factor and the reactance per unit can be calculated as well.

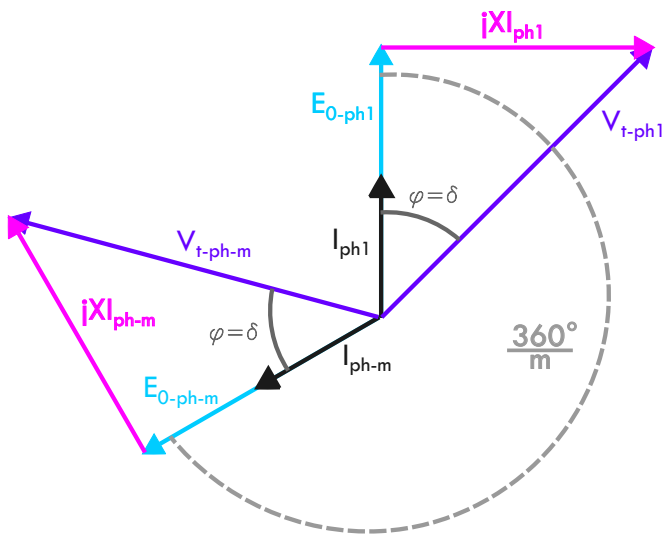

Fig. 4. Phasor diagram for m-phases with the current aligned in the q-axis.
Further, to determine the iron losses, the CAL2 method is employed [28]. For this approach, the $\alpha$ coefficient of the hysteresis loss density is set to 2 , where the eddy current coefficient is replaced by a dynamic coefficient and the anomalous losses are not present due to the accuracy of the power coefficient of 1.5 , whilst the hysteresis coefficient is kept as the Bertotti's model. The CAL2 method is expressed as follows.

$$
p_{C A L 2}=K_{h}(f, B) \cdot \hat{B}^{2} f+K_{d}(f, B) \cdot \hat{B}^{2} f^{2}
$$

According to [29], the third order polynomial to fit $K_{h}$ and $K_{d}$ for a low frequency range machine (e.g. $<400 \mathrm{~Hz}$ ) can be assumed to vary only in terms of the magnetic flux density $\hat{B}$, thus the third order polynomial curve fit for the propose of this work are described yielding

$$
\begin{aligned}
& K_{h}(\hat{B})=k_{h 0}+k_{h 1} \hat{B}+k_{h 2} \hat{B}^{2}+k_{h 3} \hat{B}^{3}, \\
& K_{d}(\hat{B})=k_{d 0}+k_{d 1} \hat{B}+k_{d 2} \hat{B}^{2}+k_{d 3} \hat{B}^{3},
\end{aligned}
$$

where $k_{h j}$ and $k_{d j}$, for $j=0,1,2,3$, are constant to be determined by the curve fit. This is done by inserting these expressions into eq. (12) and using the specific loss data for the iron core material in a curve fitting tool. This is provided in Fig. 12 in the appendix. In order to compute the losses of the machine, the calculation has to be done in time domain by time-stepping computations using FEA. In [30], the calculation of the loss density components are formulated as follows.

$$
\begin{aligned}
& p_{h}=\frac{1}{\pi T} \int_{0}^{T} K_{h}\left(f_{1}, \hat{B}\right) \cdot B(t) \cdot\left[\frac{d B(t)}{d t}\right] \cdot d t \\
& p_{d}=\frac{1}{2 \pi^{2} T} \int_{0}^{T} K_{d}\left(f_{1}, \hat{B}\right) \cdot\left[\frac{d B(t)}{d t}\right]^{2} \cdot d t
\end{aligned}
$$

Furthermore, to compute the total component losses, volumetric integration is conducted, yielding

$$
\begin{aligned}
& P_{h}=\rho l_{a} N_{\text {sector }} \iint_{S} p_{h} d S, \\
& P_{d}=\rho l_{a} N_{\text {sector }} \iint_{S} p_{d} d S,
\end{aligned}
$$

where $\rho$ is the density of the material, $l_{a}$ is the active length of the machine, $N_{\text {sector }}$ is the number of segments or sector in which the entire machine is divided to be simulated in COMSOL, and $S$ is the total integration area of the iron core of the machine.

\section{A. Power, Shear Stress and Power Factor Analysis}

The machine's power generation performance comparison is provided in Fig. 6. The rippling behaviour is even further reduced for the 13-phase machine than the 24-phase machine due to the unique phasors. Furthermore, fluctuating behaviour is observed in Arkkio's method used power calculation via the electrical torque. This is due to the Meisner Effect of the armature superconducting coils, which is better highlighted in Fig. 5. Further, it shows that the 13-phase machine has the lowest average of the airgap magnetic flux density generated by the PMs, expecting the lowest power factor among all topologies. On the other hand, the output power for the 13phase machine is increased because of the higher electrical frequency due to the 48 poles, as shown in Tables VI and VII. 
TABLE VI

Obtained Mean Electrical Power over time

\begin{tabular}{cccc}
\hline \hline Topology & FEA & Analytical $^{\mathrm{I}}$ & Deviation (\%) \\
\hline 3ph machine & $15.1871 \mathrm{MW}$ & $15.9404 \mathrm{MW}$ & $+4.7257 \%$ \\
12ph machine & $15.7861 \mathrm{MW}$ & $16.3722 \mathrm{MW}$ & $+3.5799 \%$ \\
24ph machine & $16.5837 \mathrm{MW}$ & $17.4556 \mathrm{MW}$ & $+4.9950 \%$ \\
13ph machine & $17.4137 \mathrm{MW}$ & $18.3546 \mathrm{MW}$ & $+5.1262 \%$ \\
\hline \hline
\end{tabular}

${ }^{1}$ Calculated from eq. (11) and the values obtained of the flux linkage from table VII.

TABLE VII

OBTAINED FLUX LINKAGE AND RATED FREQUENCY

\begin{tabular}{ccc}
\hline \hline Topology & Flux linkage (FEA) & Electrical frequency \\
\hline 3ph machine & $149.1473 \mathrm{~Wb}$ & $2.5200 \mathrm{~Hz}$ \\
12ph machine & $38.2969 \mathrm{~Wb}$ & $2.5200 \mathrm{~Hz}$ \\
24ph machine & $18.5595 \mathrm{~Wb}$ & $2.7720 \mathrm{~Hz}$ \\
13ph machine & $33.0260 \mathrm{~Wb}$ & $3.0240 \mathrm{~Hz}$ \\
\hline \hline
\end{tabular}

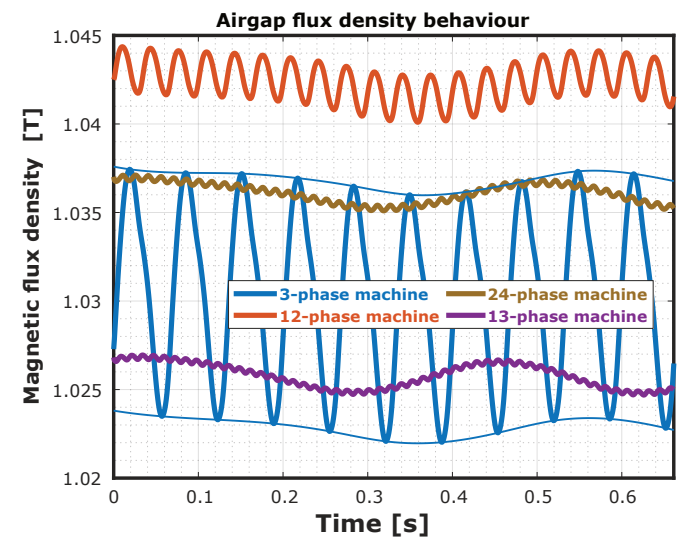

Fig. 5. Airgap magnetic flux density behaviour over time calculated inside the Arkkio's band.

According to Pyrhönen [31], the conventional shear stress for an air-cooled machines is around $59.5 \mathrm{kPa}$, so at least to double that, the shear stress of a SCM should be around $120 \mathrm{kPa}$. For the present work, the calculated shear stresses surpass this criterion. In Table VIII, the shear stress values are presented, proven to be at least three times classical machines.

TABLE VIII

OBTAINED SHEAR STRESS FOR THE STUDIED SCM TOPOLOGIES

\begin{tabular}{ccr}
\hline \hline Topology & Shear stress & Increase \\
\hline 3ph machine & $182.3180 \mathrm{kPa}$ & $0.00 \%$ \\
12ph machine & $189.4731 \mathrm{kPa}$ & $+3.92 \%$ \\
24ph machine & $199.1164 \mathrm{kPa}$ & $+9.21 \%$ \\
13ph machine & $209.0452 \mathrm{kPa}$ & $+14.66 \%$ \\
\hline \hline
\end{tabular}

By increasing the number of phases enhances, the output power and the rippling behavior is further reduced. For the 12-phase winding layout, the output power, compared to the 3phase, is enhanced even though they share the same geometry and slot-pole combination. For the 24-phase and 13-phase winding layouts, the output power is further increased due to the increase of poles, which means higher electrical frequency.

Moreover, the cogging torque is further reduced with a multiphase fractional winding layout because the LCM is further increased. For the 3-phase and 12-phase winding layouts, the LCM is 240 . For the 24-phase and 13-phase windings layouts, the LCMs are 528 and 624, respectively. Hence, the slot-pole combination can be further improved with multiphase FSCW, whilst achieving a good winding layout design.

The power factor and reactance per unit are calculated for each model, as is shown in Table IX. Compared to the reference machine, the power factor is enhanced due to the higher remanent flux density used in the magnets. On the other hand, the power factor depends on the magnetic storage capability of the PM rotor. Two main phenomena are present for a high-phase order machine that reduces the magnetic storage capability of the magnets, resulting in a lower power factor: 1) a high armature reaction that demagnetizes more the PMs; 2) the reduction in the PMs volume by increasing the number of poles for the same machine's diameter.

TABLE IX

Obtained Power Factor And Machine Reactance

\begin{tabular}{cccc}
\hline \hline Topology & Power factor $^{1}(p f)$ & Reactance $^{2}(x)$ & Reactance $^{3}(x)$ \\
\hline 3ph machine & 0.7267 & $0.6856 \mathrm{pu}$ & $0.6597 \mathrm{pu}$ \\
12ph machine & 0.7309 & $0.6800 \mathrm{pu}$ & $0.6769 \mathrm{pu}$ \\
24ph machine & 0.7184 & $0.6954 \mathrm{pu}$ & $0.7363 \mathrm{pu}$ \\
13ph machine & 0.7076 & $0.7064 \mathrm{pu}$ & $0.7346 \mathrm{pu}$ \\
\hline \hline
\end{tabular}

${ }^{1}$ Calculated with the dq voltages as follows: $V_{q} / \sqrt{V_{d}^{2}+V_{q}^{2}}$

${ }^{2}$ Calculated with the power factor as follows: $\sqrt{1-p f^{2}}$

${ }^{3}$ Calculated with the terminal voltage, Back-EMF and rated current as follows: $\sqrt{V_{t}^{2}-E_{0}^{2}} / I_{\text {rated }}$

\section{B. Space Harmonics}

The space harmonics are calculated from the airgap radial magnetic flux density as is shown in Fig. 7. The multiphase winding layouts eliminate the space sub-harmonics, which explains why the 12-phase machine gives better output than the 3-phase machine, even sharing the same geometry. Furthermore, the working space harmonic for the 13-phase winding layout is lower than the others, as shown in table $\mathrm{X}$. However, the higher electrical frequency in which the machine operates gives a better output power. Nonetheless, a high super-harmonic close to the working harmonic could be further reduced with proper winding designs.

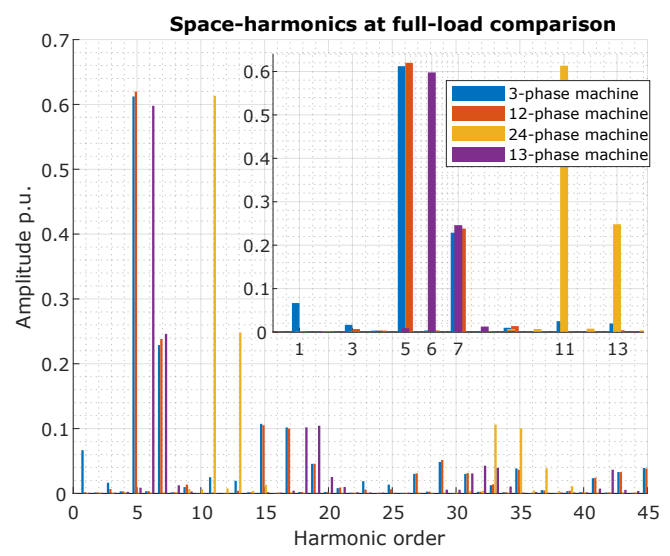

Fig. 7. Space harmonics comparison. 


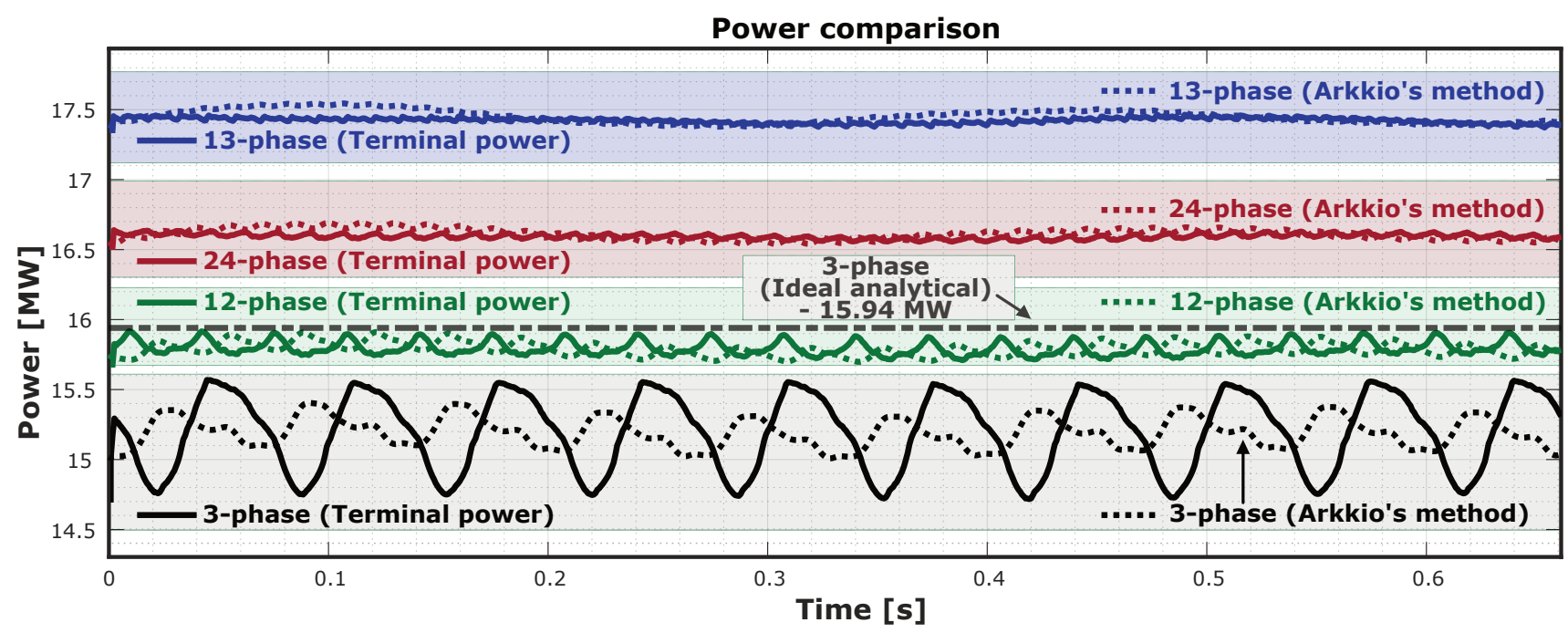

Fig. 6. Machine's power comparison with only q-axis current of $4500 \mathrm{~A}$ and mechanical speed of $72.2 \mathrm{r} / \mathrm{min}$. Arkkio's power are obtained from the Maxwell stress tensor, while the reference power calculation is made adding up the instantaneous AC power for all the phases. Straight line, obtained from eq. 11 which gives a deviation of $4.73 \%$.

TABLE X

OBTAINED SPATIAL HARMONICS

\begin{tabular}{cccc}
\hline \hline \multirow{2}{*}{ Topology } & $\begin{array}{c}\text { Sub-harmonic } \\
\text { value }\end{array}$ & \multicolumn{2}{c}{ Working Harmonic } \\
\cline { 3 - 4 } & Order & Value \\
\hline 3-phase & 0.06669 & 5 & 0.6123 \\
12-phase & 0 & 5 & 0.6199 \\
24-phase & 0 & 11 & 0.6132 \\
13-phase & 0 & 6 & 0.5979 \\
\hline \hline
\end{tabular}

\section{Iron Core Losses}

The iron losses (CAL2 method= are presented in Table $\mathrm{XI}$. Furthermore, a relative percentage comparison is made between the models in Figure 8, in which the 3-phase machine is taken as a reference, where the other topologies losses are re-computed relatively to the 3-phase machine to make a proper comparison. First, the iron losses are computed as a percentage of the total machine electrical power. This graph shows that the ripple reduction of high-phase order machines contributes to the reduction of iron losses. The advantages are clear to assess for the 12-phase machine, which has the same geometry as the 3-phase machine, shows a reduction of $14.35 \%$ in the relative iron losses. The 24-phase machine has a reduction of the percentage of iron losses compared to the 3phase machine. However, due to iron saturation and frequency operation regime, the 24-phase is not improved further than the 12-phase case. The same happens to the 13-phase machine. Nonetheless, it is essential to remark that for the 13-phase machine, the power is increased by $14.66 \%$, and the relative total iron losses are decreased $13.14 \%$ compared to the 3 phase machine.

\section{AC Superconducting Losses}

The AC losses can be reduced per every filament scribed by applying laser-scribing fabrication techniques. The wire is scribed with 10 filaments. Hence, the AC losses are reduced to a tenth of the non-scribed version. In Table XII, the AC
TABLE XI

IRON LOSSES COMPARISON.

\begin{tabular}{cccc}
\hline \hline Model & Hysteresis losses & Dynamic losses & Total iron losses \\
\hline 3ph machine & $36.4075 \mathrm{~kW}$ & $0.7481 \mathrm{~kW}$ & $37.1556 \mathrm{~kW}$ \\
12ph machine & $32.5027 \mathrm{~kW}$ & $0.5686 \mathrm{~kW}$ & $33.0712 \mathrm{~kW}$ \\
24ph machine & $35.6964 \mathrm{~kW}$ & $0.7384 \mathrm{~kW}$ & $36.4348 \mathrm{~kW}$ \\
13ph machine & $36.1478 \mathrm{~kW}$ & $0.8552 \mathrm{~kW}$ & $37.0030 \mathrm{~kW}$ \\
\hline \hline
\end{tabular}

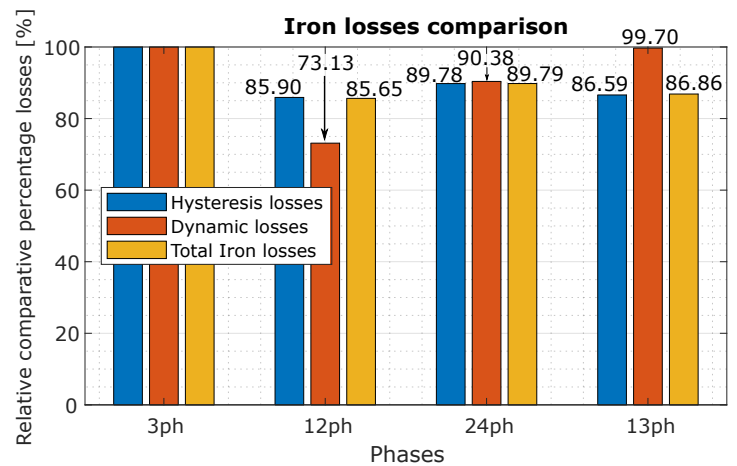

Fig. 8. Iron losses comparison. Relative comparative percentage.

TABLE XII

AC SUPERCONDUCTING LOSSES WITH OR WITHOUT LASER-SCRIBING TECHNIQUE

\begin{tabular}{ccc}
\hline \hline Model/Fabrication & Non-scribed & Scribed - 10 filaments \\
\hline 3ph machine & $83.0558 \mathrm{~kW}$ & $8.3056 \mathrm{~kW}$ \\
12ph machine & $83.6445 \mathrm{~kW}$ & $8.3645 \mathrm{~kW}$ \\
24ph machine & $72.0425 \mathrm{~kW}$ & $7.2043 \mathrm{~kW}$ \\
13ph machine & $59.7262 \mathrm{~kW}$ & $5.9726 \mathrm{~kW}$ \\
\hline \hline
\end{tabular}

losses are presented for all the models with the assumption of the laser scribing technique to reduce further the AC losses.

A good multiphase winding layout design enhances the performance by reducing the iron losses and overall rippling behavior. However, the smoothness of the magnetic flux den- 


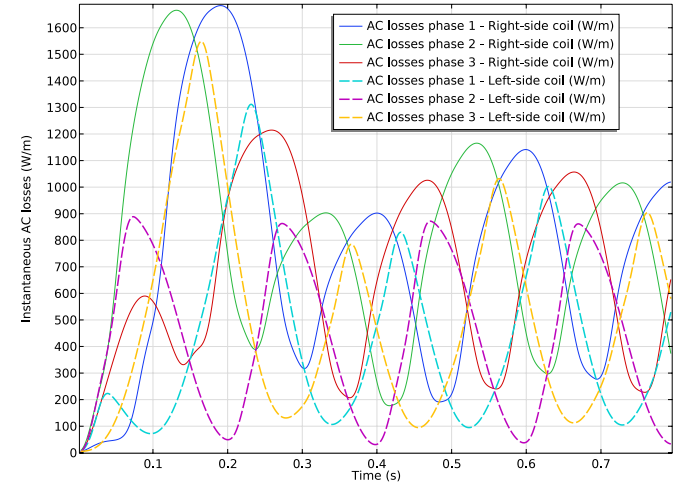

Fig. 9. Instantaneous AC losses for all the phases in a 3-phase machine. One coil side for each phase is shown to identify the different behaviour of the $\mathrm{AC}$ losses depending on the amount of magnetic flux density lines crossing the coil.

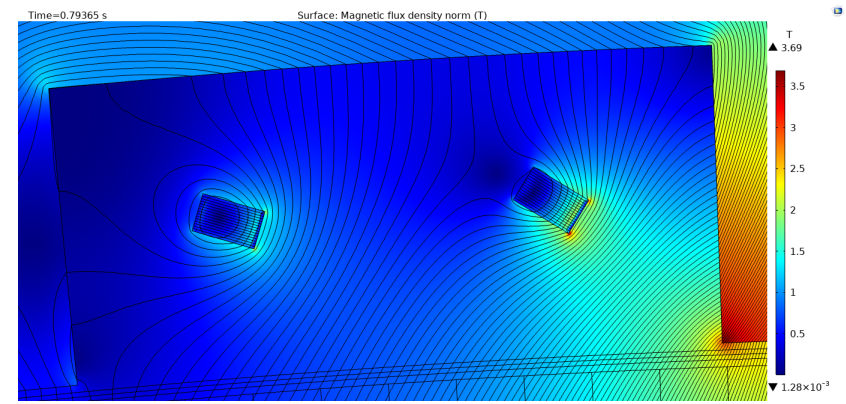

Fig. 10. Coils' angle optimization, where the left coils and right coil are at $-20^{\circ}$ and $-35^{\circ}$ measured from the horizontal axis, respectively.

sities in the air gap provided by high-phase order machines does not reduce the hysteresis $\mathrm{AC}$ superconducting losses because it depends mainly on the magnetic flux lines' tilt angle. Moreover, it is known that the stronger the armature reaction, the more tilted is the magnetic flux lines' angle. Thus, the magnetic flux lines are assessed by computing the instantaneous AC losses for the 3-phase machine for one coil side of each phase to depict the AC losses depending on the coil's location inside the slot. For example, Fig. 9 shows that the right-side coils have more $\mathrm{AC}$ losses due to there are more magnetic flux lines, hence, higher magnetic flux density in that region of the slot, as is shown in Fig. 10.

Further, a manual parametric sweep of the coil's angular position is performed in steps of $5^{\circ}$ to find a local minimum of AC losses for the 12-phase machine, as is shown in Tables XIII and XIV. With a coil's angular position of $-35^{\circ}$ for the right-side coil and $-20^{\circ}$ for the left-side coil, the AC losses are reduced up to $4.5815 \mathrm{~kW}$ for ten filaments scribed. The angle is measured with respect to the horizontal axis, and the center of the coils is the slot's center, as shown in Fig. 10. Furthermore, it is seen that the flux lines enter more perpendicular to the coil's side. In Fig. 11 it can be seen that with a reduction in the $\mathrm{AC}$ losses, the fluctuating behavior calculated with Arkkio's method increases, meaning the Meisner effect increases as well. Thus, perpendicular flux lines to the coil's side can decrease further the AC losses. However, this also creates more repulsion of the magnetic
TABLE XIII

AC LOSSES - COIL'S ANGLE DEPENDENCY

\begin{tabular}{rlr}
\hline \hline Coil angle & AC losses & Reduction \\
\hline $0^{\circ}$ & $68.2201 \mathrm{~kW}$ & $0.00 \%$ \\
$-5^{\circ}$ & $63.3444 \mathrm{~kW}$ & $-7.15 \%$ \\
$-10^{\circ}$ & $59.3590 \mathrm{~kW}$ & $-12.99 \%$ \\
$-15^{\circ}$ & $55.2684 \mathrm{~kW}$ & $-18.99 \%$ \\
$-20^{\circ}$ & $51.7830 \mathrm{~kW}$ & $-24.09 \%$ \\
$-25^{\circ}$ & $49.6070 \mathrm{~kW}$ & $-27.28 \%$ \\
$-30^{\circ}$ & $47.6165 \mathrm{~kW}$ & $-30.20 \%$ \\
$-35^{\circ}$ & $46.4383 \mathrm{~kW}$ & $-31.93 \%$ \\
$-40^{\circ}$ & $46.8285 \mathrm{~kW}$ & $-31.36 \%$ \\
$-45^{\circ}$ & $47.4000 \mathrm{~kW}$ & $-30.52 \%$ \\
\hline \hline
\end{tabular}

TABLE XIV

LEFT COIL ANGLE VARIATION

\begin{tabular}{cccr}
\hline \hline Left coil angle & Right coil angle & AC losses & Reduction \\
\hline$-30^{\circ}$ & $-35^{\circ}$ & $46.1453 \mathrm{~kW}$ & $-32.36 \%$ \\
$-25^{\circ}$ & $-35^{\circ}$ & $45.9993 \mathrm{~kW}$ & $-32.57 \%$ \\
$-20^{\circ}$ & $-35^{\circ}$ & $45.8149 \mathrm{~kW}$ & $-32.84 \%$ \\
$-15^{\circ}$ & $-35^{\circ}$ & $45.9966 \mathrm{~kW}$ & $-32.58 \%$ \\
\hline
\end{tabular}

flux densities, Meisner effect, creating a stronger magnetic flux density fluctuation in the airgap, harming the machine's mechanical integrity.

Therefore, depending on the machine's loading, the magnetic angle is further tilted, changing the superconducting $\mathrm{AC}$ losses of the coils. Thus, a design philosophy for one angular position of the armature superconducting coils at full load and/or no-load is not a good design since the superconducting AC losses are very sensitive to the magnetic flux density angle inside the slot. One solution could be a new design of the slots. However, this complicates the design of the cryocooler. Hence, a $3 \mathrm{D}$ design of the superconducting armature coils can solve the angle sensitivity by arranging twisted or non-planar coils inside the racetrack.

\section{E. Efficiency and Torque Density}

The overall efficiency is calculated as follows.

$$
\eta=\frac{P_{\text {out }}}{P_{\text {out }}+P_{\text {loss }} / C O P+P_{\text {iron }}} \times 100 \%
$$

Here, $P_{\text {out }}, P_{\text {loss }}, C O P$ and $P_{\text {iron }}$ are output power, AC losses in armature windings, coefficient of performance of cryocooler, and iron loss respectively. Here, the COP is set to 0.06 at $65 \mathrm{~K}$ according to [23].

TABLE XV

CALCULATED EFFICIENCY

\begin{tabular}{cc}
\hline \hline Topology & Efficiency $(\eta)$ \\
\hline 3ph machine & $98.8571 \%$ \\
12ph machine & $98.9192 \%$ \\
24ph machine & $99.0651 \%$ \\
13ph machine & $99.2220 \%$ \\
\hline \hline
\end{tabular}

It is shown in Table XV that the 13-phase machine has higher efficiency than the other topologies. Furthermore, in Table XVI, the highest torque-to-weight (TTW) is for the 13phase machine. In comparison to the work done by Sung et 


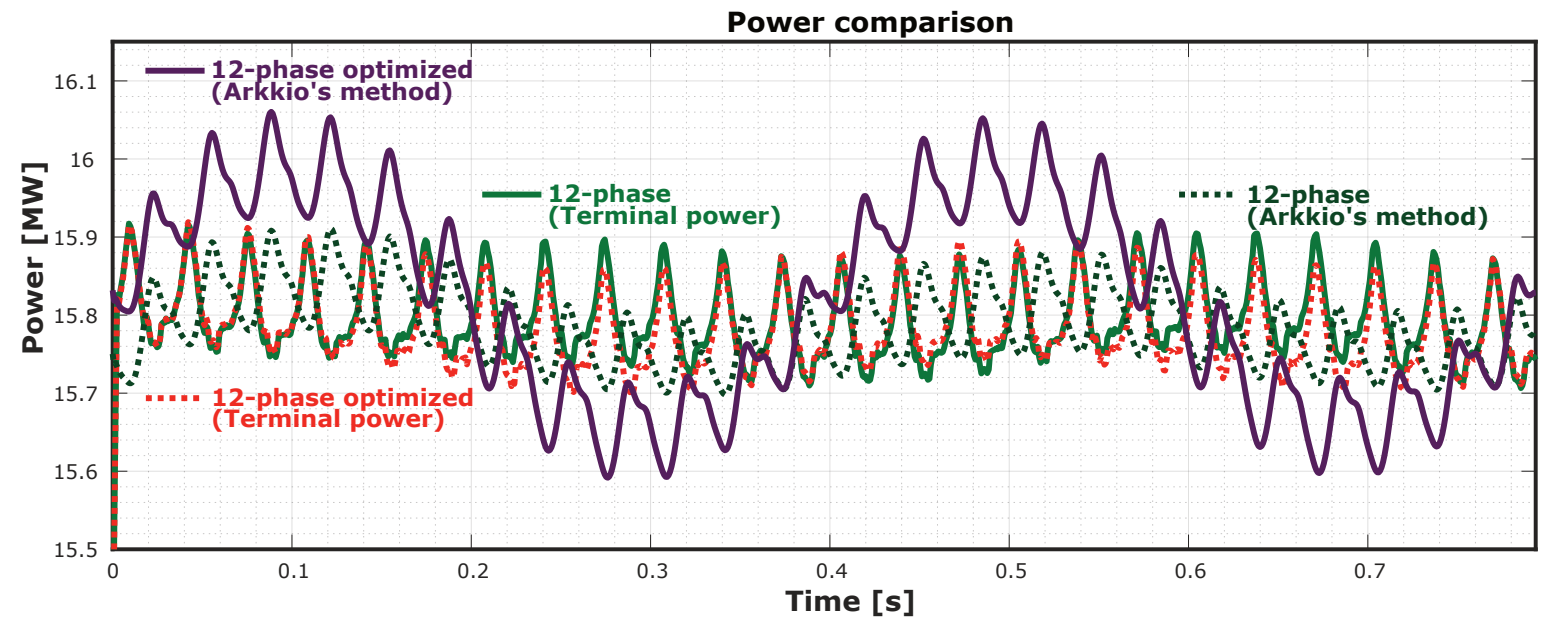

Fig. 11. Power comparison of the 12-phase and optimize version. It is depicted with the Arkkio's method calculation the Meisner effect increases when the AC losses are reduced.

TABLE XVI

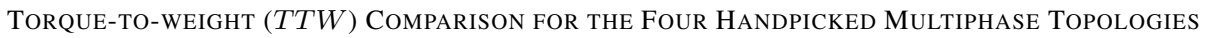

\begin{tabular}{ccccc}
\hline \hline Parameter & 3ph & 12ph & 24ph & 13ph \\
\hline$W_{\text {iron }}$ & 124.1029 ton & $124.1029 \mathrm{ton}$ & $113.8873 \mathrm{ton}$ & $103.8549 \mathrm{ton}$ \\
$W_{S C}{ }^{1}$ & $284.1975 \mathrm{~kg}$ & $284.1975 \mathrm{~kg}$ & $284.1975 \mathrm{~kg}$ & $307.8806 \mathrm{~kg}$ \\
$W_{\text {mag }}{ }^{2}$ & $14.7915 \mathrm{ton}$ & $14.7915 \mathrm{ton}$ & $14.7902 \mathrm{ton}$ & $14.7901 \mathrm{ton}$ \\
$W_{\text {total }^{3}}$ & $139.1790 \mathrm{ton}$ & $139.1790 \mathrm{ton}$ & $114.1863 \mathrm{ton}$ & $118.9529 \mathrm{ton}$ \\
\hline$T T W_{\text {active }}{ }^{4}$ & $137.8322 \mathrm{Nm} / \mathrm{kg}$ & $143.2685 \mathrm{Nm} / \mathrm{kg}$ & $183.4497 \mathrm{Nm} / \mathrm{kg}$ & $184.9122 \mathrm{Nm} / \mathrm{kg}$ \\
$T T W_{\text {Total }}{ }^{5}$ & $75.8077 \mathrm{Nm} / \mathrm{kg}$ & $78.7977 \mathrm{Nm} / \mathrm{kg}$ & $100.8973 \mathrm{Nm} / \mathrm{kg}$ & $101.7017 \mathrm{Nm} / \mathrm{kg}$ \\
\hline \hline
\end{tabular}

${ }^{1}$ The weight density of the REBCO superconducting tape is $8.19 \mathrm{~g} / \mathrm{cm}^{3}$ according to [22].

${ }^{2}$ The neodymium magnet density is set to $7.4 \mathrm{~g} / \mathrm{cm}^{3}$.

${ }^{3}$ Active weight of the machine.

${ }^{4}$ The Torque-To-Weigth is calculated with FEA values from table VII and equation 11.

5 TTW calculated by assuming a non-active mass of $55 \%$ of the total machine's weight.

al. [32] showcases an HTS field winding for a wind power generator that has a TTW of $137.3832 \mathrm{Nm} / \mathrm{kg}$ for the active weight. For the present paper, the TTW for the 3-phase machine is $137.8322 \mathrm{Nm} / \mathrm{kg}$ (i.e., only active mass, which verifies the design's effectiveness. In the end, the 13-phase machine with TTW of $184.9122 \mathrm{Nm} / \mathrm{kg}$ increases by $34 \%$ the torque density, which means that it has the highest torque density.

\section{CONCLUSIONS}

In this paper, superconducting machines (SCMs) are analyzed with multiphase topologies. It found that the use of unique phasors or an odd number of phases is an effective winding layout design since only the unique phasors reduce rippling behavior. Moreover, it is proved that the iron losses are further reduced because of the smoother behavior of the magnetic flux densities inside the iron yokes.

The use of symmetric multiphase fractional slot concentrated windings (FSCWs) can further improve the cogging torque without creating space sub-harmonics due to the slotpole combination gives higher LCMs. Furthermore, a third condition of symmetry is proposed to achieve an optimal design of a multiphase symmetric-winding SCM. Among the topologies compared, the 13-phase machine stands out by improving up to $34 \%$ in the torque density, in comparison to a conventional 3-phase machine, and with an efficiency limit of $99.2220 \%$. It is also found that the AC hysteresis superconducting losses in a low-frequency machine are strongly affected by the penetration of the magnetic flux lines into the superconductive material, which depends on the tilting angle of the flux lines. Thence, the AC losses can be further reduced by changing the tilting angle of the flux lines by increasing the armature reaction or changing the coil's angular position. However, decreasing the AC losses means that Meisner's effect is increased because there is less penetration of the magnetic flux lines. Therefore, having a strong Meisner's effect in the SCM weakens the machine's mechanical integrity by increasing the pulsating radial forces in the airgap. Thus, twisted or non-planar superconducting armature coils must be designed in 3D with a better superconducting formulation, e.g., T-A formulation, and an SC model with all the wire layers to optimize the AC losses and reduce the magnetic field's repulsion, the so-called Meisner effect.

From the findings, it is advised to build an alternating current SCM for the purpose of measuring the fluctuating magnetic behavior due to the Meisner effect and validate the results. In addition, a different PM rotor design could be achieved to improve the magnetic storage capability to enhance the power factor. On the one hand, investigate increasing the PM volume, and on the other hand, using PM Halbach 
array-based rotors. Moreover, the design of a power electronic control unit and an algorithm for high-phase order multiphase symmetric-winding is also part of future work.

\section{APPENDIX A \\ IRON MATERIAL}

The M235-A35 iron material is used in the yoke of the stator and rotor to calculate the iron losses. The B-H curve used in COMSOL is presented in fig. 12. The fitting MATLAB App generates the hysteresis and dynamic losses parameters to calculate the iron losses.

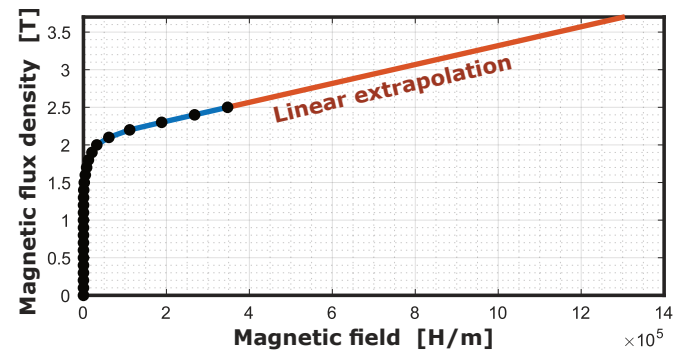

Fig. 12. Curve-fit of the B-H curve of M235-A35 lamination at room temperature.

\section{REFERENCES}

[1] D. L. Asger Bech Abrahamsen and H. Polinder, "Final assessment of superconducting (SC) and Pseudo Direct Drive (PDD) generator performance indicators (PI's). Document information," INNWIND Project, Tech. Rep. Deliverable D 3.44, 2017. [Online]. Available: https://www.innwind.eu//media/Sites/innwind/Publications/Deliverables/DeliverableD344_Final AssessmentSCandPDD_Final_27October2017_Uploaded.ashx?la=da\& hash=1E1B17BAFF6FCE3176C6356834F96495F7E1F809

[2] E. Union, "SUPRAPOWER: Superconducting, reliable, lightweight, and more powerful offshore wind turbine," This project has received funding from the European Union's Seventh Programme for research, technological development and demonstration under grant agreement number: 308793, Tech. Rep., 2017. [Online]. Available: https://cordis.europa.eu/docs/results/308/308793/final1suprapower-final-report-tecnalia-20170922-rev-1.pdf

[3] X. Song, C. Buhrer, A. Molgaard, R. S. Andersen, P. Brutsaert, M. Bauer, J. Hansen, A. V. Rebsdorf, J. Kellers, T. Winkler, A. Bergen, M. Dhalle, S. Wessel, M. T. Brake, J. Wiezoreck, H. Kyling, H. Boy, and E. Seitz, Commissioning of the World's First Full-Scale MW-Class Superconducting Generator on a Direct Drive Wind Turbine. IEEE, 2020, vol. 35, no. 3 .

[4] I. Marino, A. Pujana, G. Sarmiento, S. Sanz, J. M. Merino, M. Tropeano, J. Sun, and T. Canosa, "Lightweight $M g B_{2}$ superconducting 10MW wind generator," IOP Science : Superconductor Science and Technology, vol. 29 , no. no. 2, pp. 1-11, 2016

[5] D. Liu, "Increasing the Feasibility of Superconducting Generators for 10 MW Direct-Drive Wind Turbines,” Ph.D. dissertation, TU Delft, 2017.

[6] A. Bergen, R. Andersen, M. Bauer, H. Boy, M. ter Brake, P. Brutsaert, C. Bührer, M. Dhallé, J. Hansen, H. ten Kate, J. Kellers, J. Krause, E. Krooshoop, C. Kruse, H. Kylling, M. Pilas, H. Pütz, A. Rebsdorf, M. Reckhard, E. Seitz, H. Springer, X. Song, N. Tzabar, S. Wessel, J. Wiezoreck, T. Winkler, and K. Yagotyntsev, "Design and in-field testing of the world's first ReBCO rotor for a 3.6 MW wind generator," Superconductor Science and Technology, vol. 32, no. 12, p. 125006, dec 2019.

[7] X. Song, A. Bergen, T. Winkler, S. Wessel, M. T. Brake, J. Kellers, H. Putz, M. Bauer, H. Kyling, H. Boy, E. Seitz, C. Buhrer, P. Brutsaert, J. Krause, A. Ammar, J. Wiezoreck, J. Hansen, A. V. Rebsdorf, and M. Dhalle, "Designing and Basic Experimental Validation of the World's First MW-Class Direct-Drive Superconducting Wind Turbine Generator," IEEE Trans. Energy Convers., vol. 34, no. 4, pp. 2218$2225,2019$.
[8] T. Balachandran, D. Lee, and K. S. Haran, "Optimal design of a fully superconducting machine for 10- mw offshore wind turbines," Proc. IEEE Int. Electr. Mach. Drives Conf. (IEMDC), pp. 1903-1909, 2019.

[9] X. Huang, C. Zhou, K. Zhang, L. Wu, J. Zhang, and W. Cao, "Comparison of electromagnetic performance of scpm wind power generators with different topologies," IEEE Trans. Appl. Superconduct., vol. 29, no. 2, pp. 13-17, 2019.

[10] A. Tessarolo, "Modelling and analysis of multiphase electric machines for high-power applications," Ph.D. dissertation, University of Trieste, 2011.

[11] C. H. Lee, "Saturation Harmonics of Polyphase Induction Machines," Trans. American Inst. Electr. Eng.. Part III: Power App. Syst., vol. 80, no. 3, pp. 597-603, 1961

[12] A. S. Thomas, Z. Q. Zhu, R. L. Owen, G. W. Jewell, and D. Howe, "Multiphase Flux-Switching Permanent-Magnet Brushless Machine for Aerospace Application," IEEE Trans. Ind. Appl., vol. 45, no. 6, pp. 1971-1981, 2009.

[13] V. Kindl, Z. Ferkova, and R. Cermak, "Spatial harmonics in multi-phase induction machine," in 2020 ELEKTRO, May 2020, pp. 1-4.

[14] V. Kindl, R. Cermak, Z. Ferkova, and B. Skala, "Review of time and space harmonics in multi-phase induction machine," Energies, vol. 13, no. $2,2020$.

[15] D. Liu, X. Song, and X. Wang, "Design challenges of direct-drive permanent magnet superconducting wind turbine generators," in Proc. Int. Conf. Electr. Mach. (ICEM). Institute of Electrical and Electronics Engineers Inc., aug 2020, pp. 640-646.

[16] D. Liu, X. Song, X. Wang, M. Elhindi, U. Hasanov, X. Gou, and C. Ye, "Short-circuit characteristics of superconducting permanent magnet generators for $10 \mathrm{MW}$ wind turbines," IEEE Trans. Appl. Superconduct., vol. 31 , no. 5 , pp. $4-8,2021$.

[17] E. Snider, N. Dasenbrock-Gammon, R. McBride, M. Debessai, H. Vindana, K. Vencatasamy, K. V. Lawler, A. Salamat, and R. P. Dias, "Roomtemperature superconductivity in a carbonaceous sulfur hydride," Nature, vol. 586 , no. 7829 , pp. $373-377$, oct 2020 .

[18] M. D. Sumption, F. Wan, M. Rindfleisch, and M. Tomsic, "Ac loss of superconducting materials-refined loss estimates of mgb2 wires for superconducting motors and generators," AIAA Propulsion and Energy Forum and Exposition, 2019, no. August, 2019.

[19] K. Tsuchiya, A. Kikuchi, A. Terashima, K. Norimoto, M. Uchida, M. Tawada, M. Masuzawa, N. Ohuchi, X. Wang, T. Takao, and S. Fujita, "Critical current measurement of commercial REBCO conductors at 4.2 K," Cryogenics, vol. 85, pp. 1-7, jul 2017.

[20] F. Wan, M. D. Sumption, M. A. Rindfleisch, M. J. Tomsic, and E. W. Collings, "Architecture and Transport Properties of Multifilamentary MgB2 Strands for MRI and Low AC Loss Applications," IEEE Transactions on Applied Superconductivity, vol. 27, no. 4, pp. 1-5, 2017.

[21] R. Brambilla, F. Grilli, L. Martini, M. Bocchi, and G. Angeli, "A finite element method framework for modeling rotating machines with superconducting windings," arXiv, vol. 28, no. 5, 2017.

[22] M. Komiya, T. Aikawa, H. Sasa, S. Miura, M. Iwakuma, T. Yoshida, T. Sasayama, A. Tomioka, M. Konno, and T. Izumi, "Design Study of 10 MW REBCO Fully Superconducting Synchronous Generator for Electric Aircraft," IEEE Trans. Appl. Superconduct., vol. 29, no. 5, pp. $1-6$, aug 2019.

[23] S. Miura, M. Iwakuma, and T. Izumi, "Lightweight Design of TensMW Fully-Superconducting Wind Turbine Generators with HighPerformance REBa2Cu3Oy Wires," IEEE Trans. Appl. Superconduct., vol. 30, no. 4, pp. 3-8, 2020 .

[24] M. Komiya, R. Sugouchi, H. Sasa, S. Miura, M. Iwakuma, T. Yoshida, T. Sasayama, K. Yamamoto, A. Tomioka, M. Konno, and T. Izumi, "Conceptual Design and Numerical Analysis of 10 MW Fully Superconducting Synchronous Generators Installed with a Novel Casing Structure," IEEE Trans. Appl. Superconduct., vol. 30, no. 4, 2020.

[25] E. Gaertner, J. Rinker, L. Sethuraman, F. Zahle, B. Anderson, G. Barter, N. Abbas, F. Meng, P. Bortolotti, and W. Skrzypinski, "Definition of the IEA 15-Megawatt Offshore Reference Wind Turbine," National Renewable Energy Laboratory NREL, Tech. Rep., 2020.

[26] S. Vaschetto, A. Tenconi, and G. Bramerdorfer, "Sizing procedure of surface mounted PM machines for fast analytical evaluations," 2017 IEEE International Electric Machines and Drives Conference, IEMDC 2017, vol. 63, 2017.

[27] Z. Q. Zhu and D. Howe, "Influence of design parameters on cogging torque in permanent magnet machines," IEEE Transactions on Energy Conversion, vol. 15, no. 4, pp. 407-412, 2000.

[28] D. M. Ionel, M. Popescu, M. I. McGilp, T. J. E. Miller, S. J. Dellinger, and R. J. Heideman, "Computation of core losses in electrical machines 
using improved models for laminated steel," IEEE Trans. Ind. Appl., vol. 43, no. 6, pp. 1554-1564, Nov 2007.

[29] T. H. Akinaga, T. Staudt, W. Hoffmann, C. E. Soares, A. A. De Espindola, and J. P. Bastos, "A comparative investigation of iron loss models for electrical machine design using FEA and experimental validation," in Proc. Int. Conf. Electr. Mach. (ICEM). Institute of Electrical and Electronics Engineers Inc., oct 2018, pp. 461-466.

[30] D. M. Ionel, M. Popescu, M. I. McGilp, T. J. E. Miller, S. J. Dellinger, and R. J. Heideman, "Computation of Core Losses in Electrical Machines Using Improved Models for Laminated Steel," IEEE Trans. Ind. Appl., vol. 43, no. 6, pp. 1554-1564, 2007.

[31] J. Pyrhönen, T. Jokinen, and V. Hrabovcov, Design of Rotating Electrical Machines. Chichester, UK: John Wiley \& Sons, Ltd, dec 2008.

[32] H.-J. Sung, M. Park, B.-S. Go, and I.-K. Yu, "A study on the required performance of a 2G HTS wire for HTS wind power generators," Superconductor Science and Technology, vol. 29, no. 5, p. 054001, may 2016. [Online]. Available: https://iopscience.iop.org/article/10.1088/0953-2048/29/5/054001

Dany Josué Tomé Robles was born in Tegucigalpa, Honduras, in 1992. He received two Bachelor's degrees in Physics and Electrical Engineering from the National Autonomous University of Honduras (UNAH). He is currently finishing a joint MSc degree from the European Wind Energy Master (EWEM) program at Delft University of Technology (TU Delft), the Netherlands, and the Norwegian University of Science and Technology (NTNU), Norway. His research interests include AC superconducting coils, Multi-Phase machines, the design of compact machines, electromagnetics, Power System Analysis and Dynamics.

Robert Nilssen received the M.Sc. and Ph.D. degrees from the Norwegian University of Science and Technology (NTNU), Trondheim, Norway, in 1983 and 1989, respectively, specializing in finite-element analysis (FEA) and electrical machines (EMs). He is currently a Full Professor with the Department of Electrical Power Engineering (IEL), NTNU. His research interests include design, optimization, and modeling of industrial EMs for various applications.

Jonas Kristiansen Nøland (S'14-M'17) was born in Drammen, Norway, in 1988. He received the Ph.D. degree in engineering physics from Uppsala University, Uppsala, Sweden, in 2017. Since 2018, he has been an Associate Professor with the Norwegian University of Science and Technology. His main research interests are enabling technologies for electrification in the energy generation and transportation sectors. Dr. Nøland serves as an Editor for the IEEE TRANSACTIONS ON ENERGY CONVERSION and as an Associate Editor for the IEEE TRANSACTIONS ON INDUSTRIAL ELECTRONICS. 